\title{
Automation of a spectrophotometric method for measuring L-carnitine in human blood serum
}

\begin{abstract}
Amparo Galan, Anna Padros, Marta Arambarri and Silvia Martin

Clinical Biochemistry Service, Hospital Universitario 'Germans Trias i Pujol,' Badalona, Barcelona, Spain

A spectrometric method for the determination of $\mathrm{L}$-carnitine has been developed based on the reaction of the 5,5' dithiobis-(2nitrobenzoic) acid (DTNB) and adapted to a Technicon RA2000 automatic analyser (Quimica Farmacéutica Bayer, S.A.). The detection limit of the method is $13.2 \mu \mathrm{mol} / \mathrm{l}$, with a measurement interval ranging from 30 to $320 \mu$ mol/l. Imprecision and accuracy are good even at levels close to the detection limit (coefficient of variation of $5.4 \%$ for within-run imprecision for a concentration of $35 \mu \mathrm{mol} / \mathrm{l})$. A good correlation was observed between the method studied and the radiometric method. The method evaluated has sufficient analytical sensitivity to diagnose carnitine deficiencies. The short time period required for sample processing (30 samples in $40 \mathrm{~min}$ ), the simple methodology and apparatus, the ease of personnel training and the low cost of the reagents make this method a good alternative to the classical radiometric method for evaluating serum L-carnitine in clinical laboratories without radioactive installations.
\end{abstract}

\section{Introduction}

L-Carnitine (3-hydroxy-4-trimethyl butyric amino acid) is a synthesized quaternary amine from methionine and lysine $[1,2]$ found in the human liver, brain and kidney [3]. It is an essential cofactor for the transportation of long chain fatty acids through the mitochondrial membrane [4] thereby contributing to the beta-oxidation of the same in the liver, heart and skeletal muscle [5]. It also modulates the intracellular concentration of CoA and acetyl-CoA [6] and eliminates such non-physiologic acyl groups as the benzoic, pivalic and valproic acid [7].

A deficiency of L-carnitine means that the long chain fatty acids will not be oxidized. Clinical manifestation of this dysfunction is presented as myopathy, which may range from simple muscular weakness or slight intolerance to exercise to fatal encephalopathic episodes with hepatic dysfunction or even cardiomyopathy.

Primary L-carnitine deficiencies have been classified into two categories [8, 9]: deficiencies of exclusively muscular localization, and those of systemic involvement. Secondary L-carnitine deficiency, however, is the most common and is associated with pregnancy, malnutrition and cachexia, hepatic cirrhosis, Reye's syndrome, kidney insufficiency with haemodialysis, Fanconi syndrome, prolonged intravenous nutrition, anorexia nervosa, treatments with valproic acid and endocrinologic disorders, etc.
To diagnose these diseases, L-carnitine has to be quantified in peripheral blood and tissues. Several methods have been developed for this: spectrometric [10, 11], radiometric [12, 13], enzymatic [14], fluorometric [15, 16], chromatographic [17] and mass spectrometry [18].

Since the main interest in determining L-carnitine is for the evaluation of deficiencies, the methods used require analytical sensitivity. This condition is difficult to achieve with spectrometric and enzymatic methods, since they often have high coefficients of variation when used at levels close to the detection limit of the method. Nonetheless, these methods are the most appropriate for working in a routine clinical biochemical laboratory, given that they do not require high technology equipment, radioactive installations or highly specialized personnel.

In order to improve analytical sensitivity, precision and accuracy of the spectrometric method for evaluating carnitine, the authors adapted the 5,5'-dithiobis-(2-nitrobenzoic)acid method (DTNB) of Marquis and Fritz [10] to an automatic Technicon RA-2000 (Química Farmacéutica Bayer, S.A.) analyser. The potential of the new method was compared with the classical radiometric method proposed by Cederblad and Lindstedt [13], and modified by Barth et al. [19].

\section{Materials and methods}

Principle of the method

The method, which was initially described by Marquis and Fritz [10], is based on the reaction catalysed by the carnitine acetyltransferase (CAT) enzyme (EC 2.3.1.7) acting on L-carnitine:

L-carnitine + acetyl-CoA $\stackrel{\text { CAT }}{\longrightarrow}$ acetyl-carnitine + coenzyme A

The free coenzyme A combines with the 5,5'-dithiobis(2-nitrobenzioc) acid forming a fenolate ion spectrometrically measured at $405 \mathrm{~nm}$.

Reagents and work solutions

Reagents

- $1 \mathrm{M}$ Tris HCl, pH 7.8 (Merck cat no. 8382). Stable for at least six months stored between 2 and $8^{\circ} \mathrm{C}$.

- 5,5'-Dithiobis-(2-nitrobenzoic) acid (Boehringer Mannheim, cat no. 104477) at a concentration of $12.5 \mathrm{mM}$ in potassium carbonate at $1 \%, \mathrm{pH} 8$. Frozen in aliquots; stable for six months stored at $-20^{\circ} \mathrm{C}$. 
- $15 \mathrm{mM}$ Acetyl-coenzyme A (Boehringer Mannheim cat. no. 101893). Frozen in aliquots; stable for two months at $-20^{\circ} \mathrm{C}$.

- $50 \mathrm{mM}$ Ethylene diamine tetraacetic acid disodium salt, pH 8 (Titriplex III, Merck cat. no. 8418). Stable for at least six months stored at $4^{\circ} \mathrm{C}$.

- $20 \mathrm{U} / \mathrm{ml}$ Carnitine acetyltransferase (EG 2.3.1.7) (Boehringer Mannheim cat. no. 103241, specific activity $80 \mathrm{U} / \mathrm{mg}, 25^{\circ} \mathrm{C}$ ) in phosphate buffer $0.5 \mathrm{M}$, $\mathrm{pH}$ 7.5. Diluted 1:50 in distilled water; stable for six months at $4^{\circ} \mathrm{C}$.

- L-Carnitine internal standard: L-carnitine (Boehringer Mannheim cat. no. 836567) of 35, 77, 155, 179, 275, and $310 \mu \mathrm{mol} / \mathrm{L}$. Frozen in aliquots; stable for at least six months at $20^{\circ} \mathrm{C}$.

\section{Working solutions}

Reagent solution 1: $0.04 \mathrm{mM}$ tris-HCl buffer, $0.05 \mathrm{M}$ 5,5'-dithiobis-(2-nitrobenzoic) acid, $0.06 \mathrm{mM}$ acetylcoenzme $\mathrm{A}$ and $0.5 \mathrm{mM}$ ethylene diamine tetraacetic acid. Prepare immediately before assay.

Reagent solution 2: $0.4 \mathrm{U} / \mathrm{mL}$ carnitine acetyltransferase.

Automated assay: The working conditions in the RA-2000 analyser were as follows: type of reaction: end-point with sample blank; specimen volume: $30 \mu \mathrm{l}$; volume of the first reagent: $350 \mu \mathrm{L}$; volume of the second reagent: $50 \mu \mathrm{L}$; wavelength: $405 \mathrm{~nm}$; preincubation time: $15 \mathrm{~s}$; Incubation time; $8 \mathrm{~min}$; second reagent addition time: $1 \mathrm{~min}$; work temperature: $37^{\circ} \mathrm{C}$.

Calibration method: The method was calibrated with an Lcarnitine aqueous solution of $155 \mu \mathrm{mol} / \mathrm{l}$.

Quality control: Standards of L-carnitine were processed simultaneously with the problem samples. The assay was considered exact when the values of the standards were within $\pm 10 \%$. Imprecision was controlled with a serum pool.

Subjects: To study the reference values of the method, the blood of 100 patients from the Department of Preventive Medicine of the Hospital was used. Blood extraction was carried out after $8 \mathrm{~h}$ of fasting. All the subjects in whom the presence of associated diseases, toxic habits or drug ingestion were observed were discarded.

Sixty of these values were used to study the correlation of the method in which serum from 14 pregnant women, 21 patients on haemodialysis, three patients with hepatic cirrhosis, 10 with morbid obesity and 12 undergoing parenteral nutrition were also included.

Specimens: The blood samples $(5 \mathrm{ml})$ were extracted by the Vacutainer system in a dry tube without additives. Following retraction of the clot, the samples were centrifuged for $10 \mathrm{~min}$ at $3000 \mathrm{rpm}$. The resulting serum was deproteinized following the procedure described by Rodriguez-Segade et al. [20]: approximately $1 \mathrm{ml}$ of serum was kept in a water bath at $100^{\circ} \mathrm{C}$ for $5 \mathrm{~min}$. After being maintained at $-20^{\circ} \mathrm{C}$ for $40 \mathrm{~min}$ the serum was pricked with a needle tip until totally thawed and centrifuged at $15000 \mathrm{rpm}$ for $15 \mathrm{~min}$. The clear supernatant obtained after centrifugation was the specimen used to determine free carnitine.

Evaluation of the method: The analytical interval and the detection limit of the method were evaluated following the directions of the Societé Française de Biologie Clinique [21]. To calculate the analytical interval standard aqueous solutions of L-carnitine were used. The detection limit was established following the processing of 10 specimens of distilled water. With the mean (md) and the standard deviation (SD) the detection limit for an $\alpha$ and $\beta$ risk of $5 \%$ was calculated ( $\mathrm{Ld}=\mathrm{md}+K \mathrm{SD})$.

The recommendations of the European Committee for Clinical Laboratory Standards (ECCLS) were followed for the study of the imprecision and inaccuracy of the method [22].

To determine the analytical recovery, increasing quantities of L-carnitine were added to different aliquots of sera pool. The dilution effect was corrected by adding the same volume of saline solution to aliquot lanes. The reference values of the method were obtained following the recommendations of the Panel of Experts of the IFCG in reference values [23].

Correlation of the study method with the radiometric method: $\mathrm{L}-$ Carnitine was determined in 120 samples simultaneously by two methods: the study method and a radiometric method. The latter was a modification of the method by Cederblad and Lindstedt [18] proposed by Barth et al. [19].

Statistical methods: Mean, standard deviation and coefficient of variation for studying the accuracy, imprecision and detection limit. Deming's regression analysis was also used to study the correlation of methods.

To calculate the reference values of the method, the 2.5, 50 and 97.5 percentiles (P2.5, P50, and P97.5) were used.

Practicability study: To assess the practicability of the method, the following aspects were taken into account: the installations and apparatus required, training of personnel, time and performance of the assay (preparation of reagents, treatment of the sample, processing of specimen), expiry dates and costs of the reagents. The practicability of the method was compared with that of the radiometric method (taken as the reference).

\section{Results}

Detection limit and analytical interval. The detection limit established for the method was $13.2 \mu \mathrm{mol} / 1$. The analytical interval of the method ranged from 30 to $320 \mu \mathrm{mol} / \mathrm{l}$. Figure 1 shows the slope of linear regression of the least squares $(y=0.9 x+6.0 ; r=0.98)$ established among the theoretical values $(x)$ of the six L-carnitine reference 
standards, processed in triplicate over three consecutive days, and the values found $(y)$.

Imprecision and inaccuracy. Table 1 demonstrates the within-run and between-run coefficients of variation of the aqueous internal standards of L-carnitine at three concentration levels, as well as those of the serum specimen. The percentages of inaccuracy with respect to the theoretical value (table 2) did not exceed $10 \%$

Analytical recovery study. Analytical recovery of L-carnitine accounted for 89 to $97 \%$ (see table 3 ).

Reference values. The reference interval for the whole population studied ranged from 52 to $96.8 \mu \mathrm{mol} / \mathrm{l}$.

Table 1. Method imprecision.

\begin{tabular}{cccc}
\hline & $n$ & $\begin{array}{c}\text { Within-run } \\
\text { CV }(\%)\end{array}$ & $\begin{array}{c}\text { Between-run } \\
\text { CV }(\%)\end{array}$ \\
\hline $\begin{array}{c}\text { Aqueous L-carnitine } \\
\text { solution }(35 \mu \mathrm{mol} / \mathrm{l})\end{array}$ & 20 & 4.9 & 5.4 \\
$\begin{array}{c}\text { Aqueous L-carnitine } \\
\text { solution }(170 \mu \mathrm{mol} / \mathrm{l})\end{array}$ & 20 & 4.6 & 4.9 \\
$\begin{array}{c}\text { Aqueous L-carnitine } \\
\text { solution }(275 \mu \mathrm{mol} / \mathrm{l})\end{array}$ & 20 & 1.5 & 4.3 \\
\hline
\end{tabular}

Correlation with the radiometric method. The slope of the linear regression of least squares between the colorimetric method $(y)$ and the radiometric method $(x)$ was $y=1.24 x+8.60$ and linear coefficient of correlation of Pearson was 0.77 (see figure 2). Deming's regression analysis $(b=1.3528, a=3.969)$ shows that the method measures values higher than the radiometric method.

Practicability of the method. Table 4 shows the features studied in order to evaluate the practicability of the method in comparison with the classical radiometric method.

\section{Discussion}

The main clinical application of the evaluation of $\mathrm{L}$ carnitine is for evaluating L-carnitine deficiency in human serum or tissues. The enzymatic [14] and spectrometric methods [10] for quantifying this biochemical magnitude generally have low analytical sensitivity for evaluating L-carnitine levels below the reference interval of the method. The coefficients of variation in these ranges are high. The problem is exacerbated with the deproteinization process required for the sample [10, 24], since the treatment with the deproteinization method

Table 2. Inaccuracy.

\begin{tabular}{|c|c|c|c|c|c|}
\hline \multirow[b]{2}{*}{$\begin{array}{c}\text { Concentration (theoretical) in } \\
\mu \mathrm{mol} / l\end{array}$} & \multirow[b]{2}{*}{$n$} & \multicolumn{2}{|c|}{ Within-run } & \multicolumn{2}{|c|}{ Between-run } \\
\hline & & $\begin{array}{l}\text { Concentration found } \\
\qquad(\mu \mathrm{mol} / l)\end{array}$ & Inaccuracy $(\%)$ & $\begin{array}{l}\text { Concentration found } \\
\qquad(\mu \mathrm{mol} / l)\end{array}$ & Inaccuracy $(\%)$ \\
\hline 77 & 20 & 72.2 & 6.2 & 74 & 3.9 \\
\hline 155 & 20 & 164.5 & 6.1 & 163 & 5.1 \\
\hline 310 & 20 & 300 & 3.3 & 301 & 2.9 \\
\hline
\end{tabular}

Table 3. Recovery study.

\begin{tabular}{ccccc}
\hline $\begin{array}{l}\text { Serum pool } \\
(\mu \mathrm{mol} / l)\end{array}$ & $\begin{array}{c}\text { L-carnitine } \\
\text { added }(\mu \mathrm{mol} / l)\end{array}$ & $\begin{array}{c}\text { Theoretical carnitine } \\
\text { concentration }(\mu \mathrm{mol} / l)\end{array}$ & $\begin{array}{c}\text { Carnitine concentration } \\
\text { found }(\mu \mathrm{mol} / l)\end{array}$ & Recovery $(\%)$ \\
\hline 68.3 & 186 & 254 & 228 & 90 \\
68.3 & 124 & 192 & 170 & 89 \\
34.1 & 62 & 96 & 95 & 97 \\
16.7 & 31 & 47.7 & 46 & 95 \\
\hline
\end{tabular}

Table 4. Practicability of the spectrometric method versus the radiometric method.

\begin{tabular}{lll}
\hline & \multicolumn{1}{c}{ Radiometric method } & \multicolumn{1}{c}{ Spectrometric method } \\
\hline Type of installation & Radioactive & Conventional \\
Apparatus & B-Scintillation counter & Automatic analyser or \\
& Refridgerated centrifuge & spectrometer \\
Personnel training & Requires title of radiosotope manipulator & Approximately $2 \mathrm{~h}$ \\
Response time & $24 \mathrm{~h}$ & 50 min \\
Sample pretreatment & Not required & Automatic: 9 min. \\
Sample processing & Manual: $2 \mathrm{~h}$ and & \\
& posterior radioactivity count & \\
Reagents & Longer and more difficult than in the radiometry & Relatively simple \\
Reagent preparation & Long & Six months \\
Expiry date of reagents & & 2.3-fold lower than radiometric method \\
Cost of reagents & &
\end{tabular}




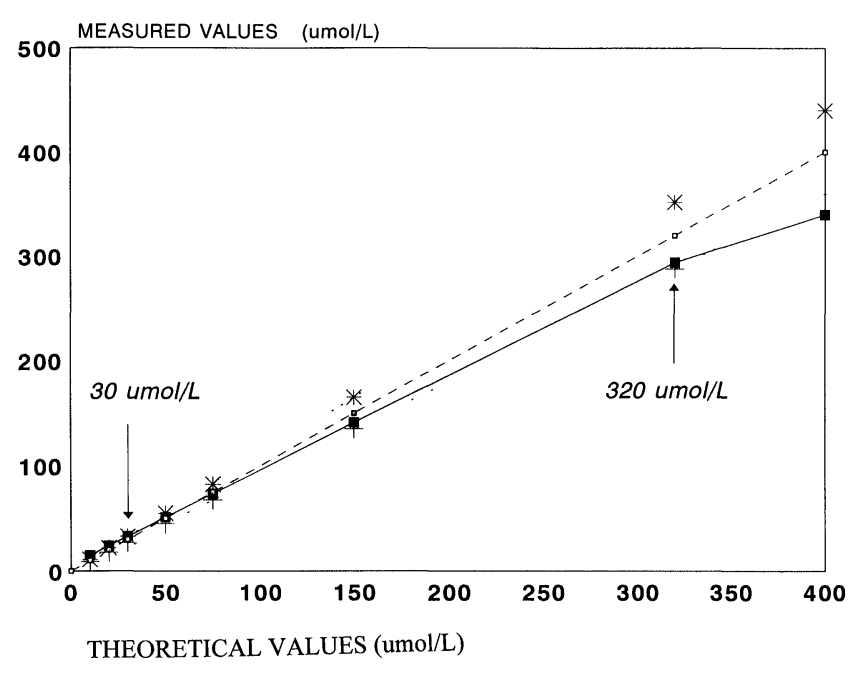

Figure 1. Analytical interval: reference line (-口-) $\mathrm{y}=\mathrm{bx}(\mathrm{b}=1)$ and 2 standard deviations of reference line $\mathrm{y}=\mathrm{x}(+),(*)$. The points from 30 to $320 \mu \mathrm{mol} / 1$ on the experimental line $(\mathrm{y}=0.9 \mathrm{x}+6)(-\mathrm{Q}-)$ cross either directly or at least in the range of their 2 standard deviations the reference line.

SPECTROMETRIC (U MOI/L)

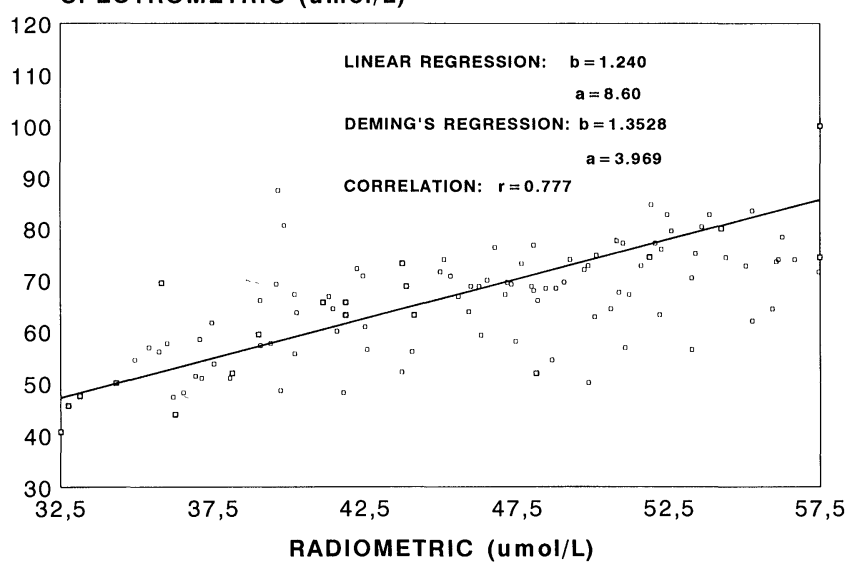

Figure 2. Correlation between the radiometric and the colorimetric method.

often leads to an even greater decrease in carnitine concentration.

With the proposed method the analytical sensitivity at low levels markedly improved, the between-run coefficient of variation for a concentration of $35 \mu \mathrm{mol} / 1$ was $5.4 \%$. This concentration is lower than the low interval of the method reference value $(52 \mu \mathrm{mol} / \mathrm{l})$ and is close to the $13.2 \mu \mathrm{mol} / 1$ of the detection limit. The improvement achieved is due to the automatization process of the spectrometric method of the 5,5'-dithiobis-(2-nitrobenzoic) acid, and also to the use of thermic deproteinization described by Rodriguez-Segade et al. [20] which, among other advantages, avoids any dilution of the sample. On adapting the technique by Marquis and Fritz [10], an automatized method is able to markedly save the volume of the deproteinized sample. Thirty microlitres were used versus the $1 \mathrm{ml}$ required by the original technique.
From a practical point of view, the adapted method has advantages over the radiometric method. The results were obtained quickly, with 30 deproteinized samples being processed in $40 \mathrm{~min}$. The cost of the reagents is 2.3fold less than that of the radiometric method. Moreover, training of personnel for performing this technique is relatively simple and the apparatus required are generally found in a conventional clinical laboratory. The radiometric methods used as reference methods (because of their greater analytical sensitivity) present the inconveniences of using radioisotopes requiring radioactive installations which not all clinical laboratories possess. Thus, the evaluation presented demonstrates excellent applicability, particularly for laboratories without radioactive installations.

The method developed and presented in this study has sufficient analytical sensitivity to evaluate defiencies in serum carnitine. This method may substitue the classical radiometric method and should be considered in clinical laboratories without radioactive installations.

\section{References}

1. Tanphaichitr, V. and Broquist, H. P., 1973, Journal of Biological Chemistry, 248, 2176.

2. Wolf, G. and Berger, C. R. A., 1961, Arch. Biochem. Biophys., 92, 360

3. Reboughe G. J. and Engel, A. G., 1980, Biochimica Biophysica Acta, 630, 22.

4. Stumpf, D. A., Parker, W. D. and Angelini, C., 1985, Neurology, 35, 1041 .

5. Pande, S. V. and Parvin, R., 1980, Fournal of Biological Chemistry, 255, 2994.

6. Ghalmers, R. A., Roe, G. R., Stacey, T. E. and Hoppel, C. L., 1984, Pediatric Research, 18, 1325.

7. Millintong, D. S., Bohan, T. P., Roe, C. R., Yergey, A. L. and Liberato, D. J., 1985, Clinica Chimica Acta, 145, 69.

8. Dipalma, J., 1988, American Family Physician, 38, 243.

9. Siliprandi, N., Sartorelli, L., Ciman, M. and Di Lisa, F., 1989, Clinica Chimica Acta, 183, 3.

10. Marquis, N. R. and Fritz, L. B., 1964, Journal of Lipid Research, 5, 184.

11. Segcombe, D., Dodek, P., Frohligh, J., Hahn, P., Skala, J. and Campbell, D., 1976, Clinical Chemistry, 22, 209.

12. Barns, R., Bowling, F., Brown, G., Glague, A. and Thompson, A., 1991, Clinica Chimica Acta, 197, 27.

13. Gederblad, G. and Lindstedt, S., 1972, Clinica Chimica Acta, 37, 235.

14. Wieland, O. H., 1985, In Methods of Enzymatic Analyses, Ed. Bergmeyer, H. U. (Weinheim: VCH Verlagsgesellschaft).

15. Matsumoto, K., Yamada, Y., Takahashi, M., Todoroki, T., Mizoguahi, K., Misaki, H. and Yuki, H., 1990, Clinical Chemistry, $36,2072$.

16. Maehara, M., Kinoshita, S. and Watanabe, K. , 1988, Clinica Chimica Acta, 171, 311.

17. Weading, G. P., Mills, G. A. and Walker, V., 1988, Annals of Clinical Biochemistry, 25, 233s.

18. Kodo, N., Millington, D., Norwood, D. and Roe, G. 1989, Clinica Chimica Acta, 186, 383.

19. Barth, P. G., Scholte, H. R., Berden, J. A. et al., 1983, Journal of the Neurological Sciences, 327.

20. Rodriguez-Segade, S., Alonso de la Peña, G., Paz, J. M. and Del Río, R., 1985, Clinical Chemistry, 31, 754.

21. Societé Française de Biologie Clinique, 1986, Ann. Biol. Clin., 44, 686.

22. European Commitee for Clinical Laboratory Standards, 1986, Guidelines for the Evaluation of Analyzers in Clinical Chemistry, ECCLS Document.

23. International Federation of Clinical Chemistry, 1987, Clinica Chimica Acta, 170, s13.

24. Fishlock, R. G., Bieber, L. L. and Snoswell, A. M., 1984, Clinical Chemistry, 30, 316. 


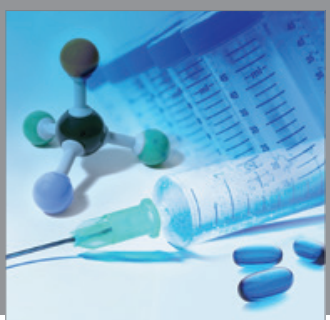

International Journal of

Medicinal Chemistry

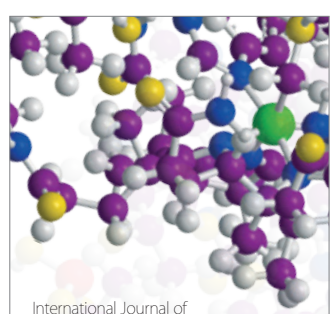

Carbohydrate Chemistry

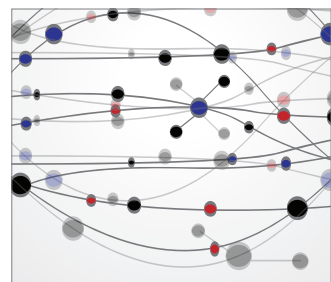

The Scientific World Journal
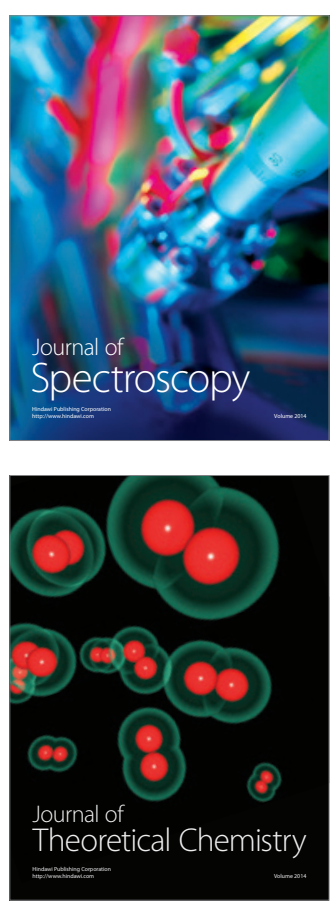
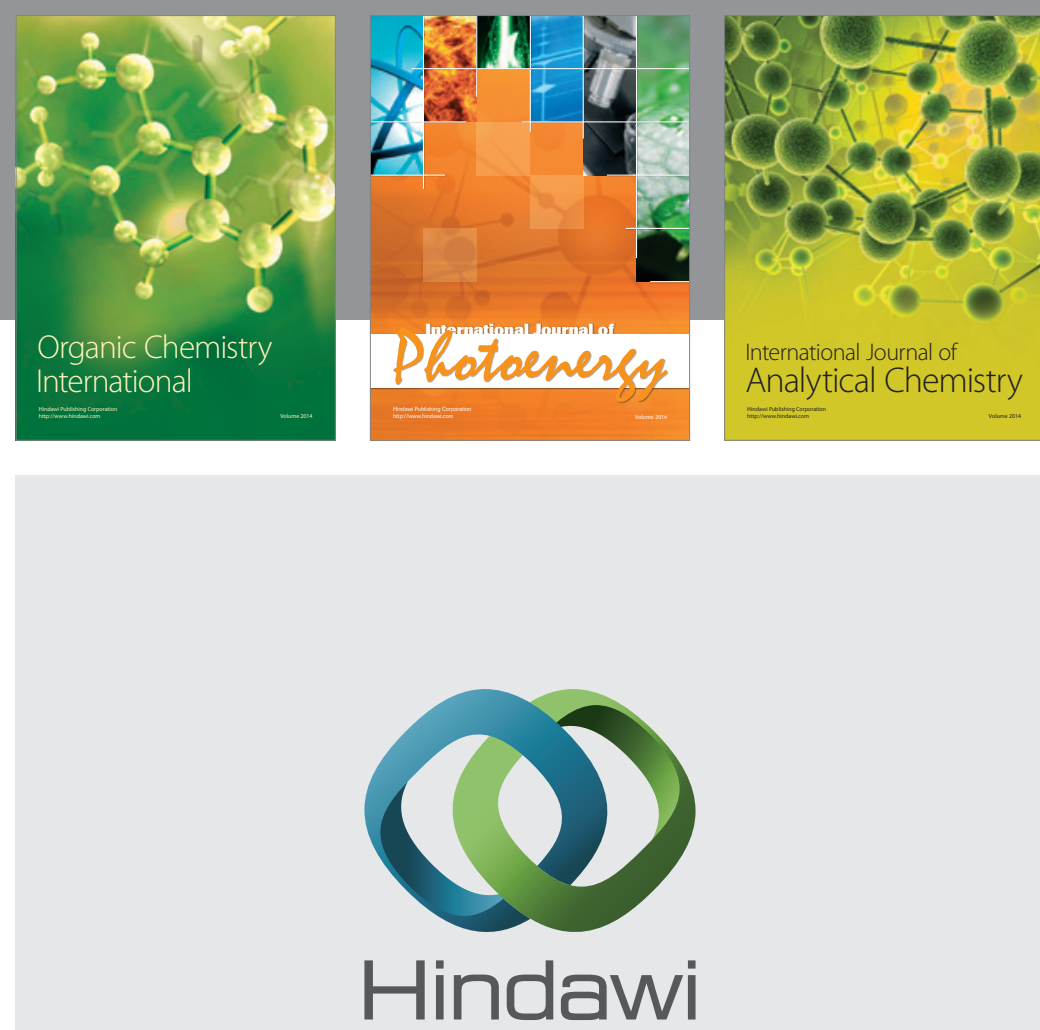

Submit your manuscripts at

http://www.hindawi.com
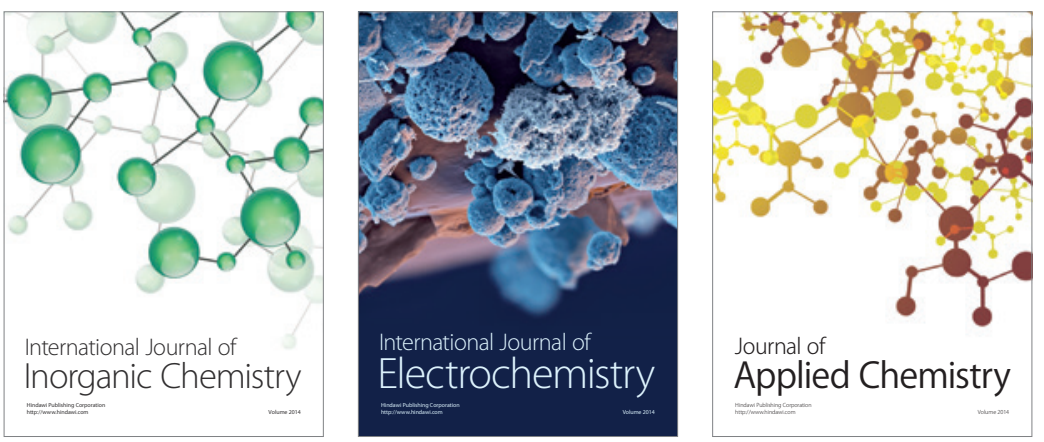

Journal of

Applied Chemistry
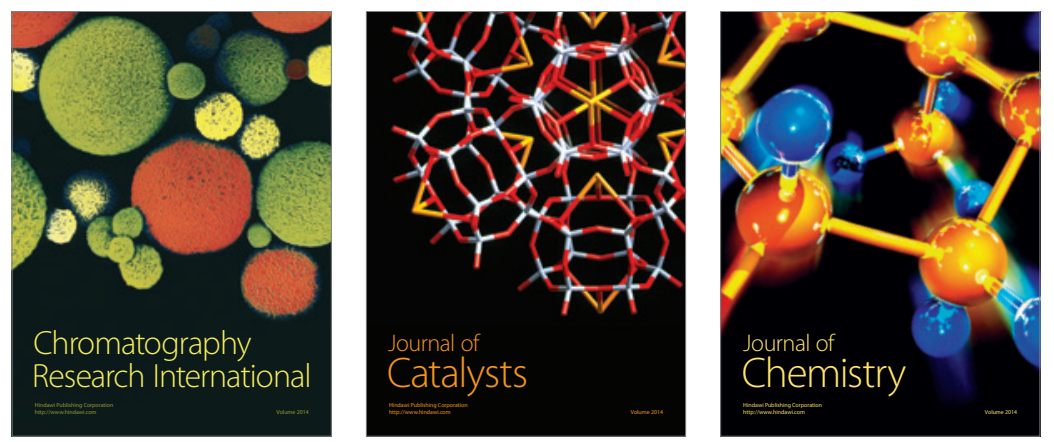
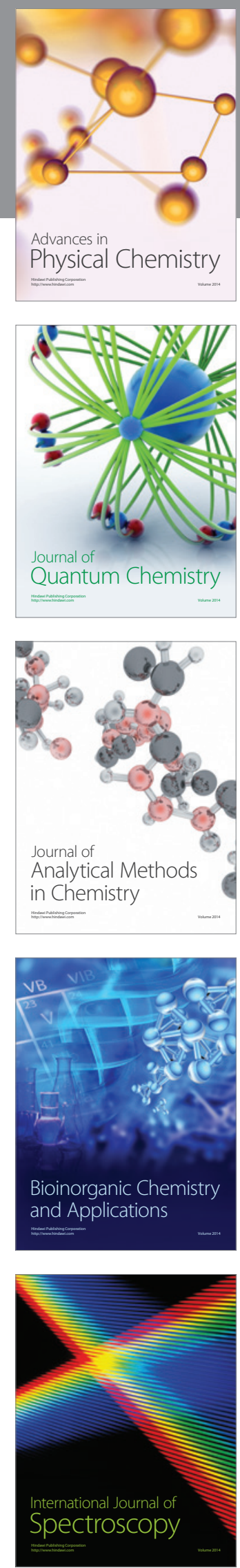